\title{
Development and Evaluation of Two Pecan Scab Prediction Models
}

\author{
A. F. Payne and D. L. Smith, Department of Entomology and Plant Pathology, Oklahoma State University, Stillwater 74078
}

\begin{abstract}
Payne, A. F., and Smith, D. L. 2012. Development and evaluation of two pecan scab prediction models. Plant Dis. 96:117-123.

Fusicladium effusum (syn. Cladosporium caryigenum), causal agent of pecan scab, is the most economically important pathogen of pecan (Carya illinoinensis). A weather-based advisory is currently used in Oklahoma to assess the need for fungicide application and requires the accumulation of scab hours. A scab hour is defined as an hour of average temperature and relative humidity $\geq 21.1^{\circ} \mathrm{C}$ and $90 \%$, respectively. To assess the validity of the thresholds in the advisory, repeated ratings of disease severity were taken on fruit each year during the 1994-96 and 2009-10 growing seasons. Hourly weather variables were also examined, including temperature, relative humidity, dew point, dew point depression, total solar radiation, and total rainfall. Rain and disease severity were converted to binomial variables where a rain event $(\geq 2.5 \mathrm{~mm})$ and disease severity $(\geq 25 \%)$ were coded as 1 and all other events as 0 . Logistic regression models adjusted for correlated data were developed using generalized estimating equations. Two models were developed: a temperature/relative humidity model and a dew

point/dew point depression model. For the temperature/relative humidity model, the best fitting model included all main effects. Using this model, validation exercises assuming no rain and total solar radiation of $22.5 \mathrm{MJ} \mathrm{m}^{-2}$ resulted in a 0.62 probability of pecan scab development when the temperature was $21^{\circ} \mathrm{C}$ and relative humidity was $90 \%$. Findings of this model were further validated during field studies that evaluated different combinations of temperature and relative humidity thresholds for scheduling fungicide applications. These analyses indicated that the current thresholds of temperature and relative humidity are viable but a modification of the relative humidity component should be considered. For the dew point/dew point depression model, a reduced model, including dew point, dew point depression, and the binomial rain variable, was considered adequate for explaining scab events, which suggests that future model building to describe pecan scab epidemics should include dew point, dew point depression, rain, and total solar radiation as independent variables.
\end{abstract}

Fusicladium effusum (G. Winter) (syn. Cladosporium caryigenum (Ellis \& Langl.) Gottwald), the causal agent of pecan scab, is the most economically important fungal pathogen of pecan (Carya illinoinensis (Wangenh.) K. Koch). During severe epidemics of pecan scab, kernel quality can be reduced and crop losses can be high $(9,12)$. F. effusum overwinters as stroma on infected shoots and fruit shucks from the previous season. When springtime temperatures begin to warm, conidia are liberated from the stroma and serve as primary inoculum. Symptoms of pecan scab can occur as early as budbreak in Oklahoma, initially as small, gray-green lesions that develop into larger, dark-brown lesions $(6,9)$. Expanding leaves and twigs are the first plant parts infected. Fruit are infected via primary and secondary inoculum produced on leaves and twigs $(6,12)$. In controlled environment studies using leaves and 48 -h wetting periods, $F$. effusum grew optimally at 15 to $25^{\circ} \mathrm{C}$ and produced the greatest number of lesions at $20^{\circ} \mathrm{C} \mathrm{(8)}$.

Current pecan scab management practices rely heavily on the use of fungicides to protect trees from the disease. In order to facilitate proper timing of fungicide applications, the Oklahoma Agweather Pecan Scab Fungicide Advisory (OAPSFA) was developed in the mid-1990s. The parameters of the model used in the OAPSFA were developed through a simple analysis of pecan scab increase compared with hours of weather conducive for disease development (7). Inputs for the model include air temperature and relative humidity to determine "scab hours". A scab hour is defined as an hour in which the average air temperature is $\geq 21.1^{\circ} \mathrm{C}$ and the relative humidity is $\geq 90 \%$. Scab hours are accumulated over a $14-$ day window after the assumed 14-day protection period has ended following a fungicide application. Fungicide applications are not advised until 10 scab hours, 20 scab hours, or 30 scab hours have accumulated over the 14-day period for susceptible, moderately

Corresponding author: A. Payne, E-mail: andrea.payne@ okstate.edu

Accepted for publication 25 August 2011.

http://dx.doi.org/10.1094/PDIS-03-11-0202

(C) 2012 The American Phytopathological Society susceptible, and resistant cultivars, respectively (28). The scab hour thresholds were developed by Driever (7) based on regression analysis, which demonstrated a correlation between number of hours that weather was favorable for scab and differential cultivar susceptibility. For the OAPSFA, temperature and relative humidity data are collected from the Oklahoma Mesonet weather station network (www.mesonet.org) at a standard height of $1.5 \mathrm{~m}$ above the ground. In Oklahoma, the OAPSFA can recommend from 1 to 10 fungicide applications per season depending on weather and the cultivars being grown. However, the average number of fungicide applications is approximately five per season.

Recently, growers have questioned the performance of the spray advisories, resulting in speculation that the model may not be accurately identifying periods favorable for pecan scab epidemics. Growers perceive that the model does not accurately predict scab increases when increase in disease is observed in the field. These perceived inaccuracies in the advisory could be from three sources. First, weather stations are located in areas that may not be representative of the microclimate typically found in Oklahoma pecan groves. Pecan groves tend to be in low-lying areas or near bodies of surface water, which can dramatically change the microclimate. Another explanation for the inaccuracy of the advisory might be that pertinent weather variables are missing from the model. Finally, current temperature or relative humidity thresholds may be incorrect. The current thresholds were set to reflect levels of temperature and relative humidity known to be biologically significant for symptom development. The temperature threshold was based on research in Georgia (9) and Oklahoma (7), which indicated that temperatures $\geq 21.1^{\circ} \mathrm{C}$ correlated with increases of pecan scab. Gottwald (8) reported that isolates of F. effusum were capable of infecting leaves at temperatures of 15 to $25^{\circ} \mathrm{C}$. Turechek and Stevenson (25) found similar trends, with infection and disease development occurring at temperatures as low as $15^{\circ} \mathrm{C}$ and no infection or disease development at $35^{\circ} \mathrm{C}$. Considering the wide range in temperatures for scab development, the current threshold of $21.1^{\circ} \mathrm{C}$ in the OAPSFA might be set too high. This could result in false negatives for fungicide spray recommendations, resulting in an increase in disease despite no warning given by the advisory. 
For the current Oklahoma advisory program, a relative humidity threshold for scab of $90 \%$ was selected to estimate wetting events that corresponded to an increase in pecan scab (7). Relative humidity can be used to estimate wetting events and a value of $\geq 90 \%$ is a suitable indicator (15). However, in some locations such as the upper Midwestern United States, leaf wetness has been reported to occur at lower thresholds of relative humidity from 83 to $85 \%$ (21). In Oklahoma, leaf-wetting events have been observed at relative humidity values as low as $85 \%$ (D. L. Smith, unpublished data). Considering the wide variation in temperatures at which $F$. effusum infects and causes disease, and the lower relative humidity thresholds that may correlate with leaf-wetting events, the current advisory may need modification to improve prediction accuracy. Also, other weather variables such as dew point or rain events should be considered as inputs. Therefore, the objectives of this study were to evaluate the thresholds used by the current fungicide advisory program and determine whether the addition or substitution of other weather variables can improve pecan scab risk predictions.

\section{Materials and Methods}

2009-10 Field trials. Field trials were conducted on a commercial farm near Madill, OK. Trees were planted on a Madill fine sandy loam soil located on a lowland site in 2002. Bare root transplants consisted of 'Pawnee' scion grafted to 'Apache' rootstock. Pawnee is considered to be moderately susceptible $(7,28)$. Trees were spaced $12.2 \mathrm{~m}$ apart with a between-row spacing of $12.2 \mathrm{~m}$. Treatments consisted of applying fungicides according to the OAPSFA with various modifications to the air temperature and relative humidity combinations required to calculate a scab hour. These included air temperature/relative humidity thresholds of $15.5^{\circ} \mathrm{C} / 80 \%, 18.3^{\circ} \mathrm{C} / 80 \%, 15.5^{\circ} \mathrm{C} / 85 \%, 21.1^{\circ} \mathrm{C} / 90 \%$ (positive control), and no thresholds (negative control). The temperature thresholds were chosen in order to examine temperature influences that span the lower range of temperatures known to be favorable for pecan scab development. Relative humidity thresholds were based on previous reports that leaf wetness could be estimated using relative humidity thresholds lower than 90\%. Likely combinations of thresholds were included in this study but, because of limited research trees, all possible combinations of thresholds were not examined. At least two border trees separated each plot that received a treatment. The first fungicide applications for each treatment were applied at the parachute stage of leaf development during the prepollination period, which corresponded to 19 May 2009 and 28 April 2010. Subsequent applications were applied according to the treatment thresholds after 20 scab hours accumulated (moderately susceptible cultivar). The experimental

Table 1. Dates of fungicide applications made according to the experimental thresholds examined during the 2009 and 2010 growing seasons using the moderately susceptible 'Pawnee'

\begin{tabular}{lccc}
\hline Treatment & Application & $\mathbf{2 0 0 9}^{\mathbf{z}}$ & $\mathbf{2 0 1 0}$ \\
\hline Nontreated & N/A & N/A & N/A \\
$21.1^{\circ} \mathrm{C} / 90 \%$ & 1 & 29 June & 8 June \\
& 2 & 31 July & 28 June \\
$15.5^{\circ} \mathrm{C} / 85 \%$ & 1 & 12 June & 18 May \\
& 2 & 1 July & 4 June \\
& 3 & 31 July & 24 June \\
$18.3^{\circ} \mathrm{C} / 80 \%$ & 4 & 14 August & 16 July \\
& 1 & 12 June & 18 May \\
& 2 & 1 July & 4 June \\
$15.5^{\circ} \mathrm{C} / 80 \%$ & 3 & 31 July & 28 June \\
& 4 & 25 August & 20 July \\
& 1 & 10 June & 18 May \\
& 2 & 29 June & 4 June \\
& 3 & 23 July & 24 June \\
& 4 & 14 August & 16 July \\
\hline
\end{tabular}

${ }^{\mathrm{z}}$ Experimental thresholds were initiated following an initial fungicide application made during the parachute stage of leaf development, prior to pollination on 19 May in 2009 and 28 April in 2010. N/A = not applicable. design in both years was a randomized complete block design with five replicates. In 2009, fungicides used were a rotation of fenbuconazole at $0.14 \mathrm{~kg}$ a.i./ha (Enable; Dow AgroSciences), azoxystrobin at $0.25 \mathrm{~kg}$ a.i./ha + propiconazole at $0.16 \mathrm{~kg}$ a.i./ha (Quilt; Syngenta Crop Protection), and azoxystrobin at $0.22 \mathrm{~kg}$ a.i./ha (Abound; Syngenta Crop Protection). During the 2010 growing season, fungicides used were a rotation of tebuconazole at $0.25 \mathrm{~kg}$ a.i./ha (Folicur; Bayer CropScience), thiophanate-methyl at 0.70 $\mathrm{kg}$ a.i./ha (Topsin 4.5FL; United Phosphorus), and azoxystrobin at $0.22 \mathrm{~kg}$ a.i./ha (Abound; Syngenta Crop Protection). Fungicides were applied with a tractor-mounted air-blast sprayer (Savage Equipment), calibrated to deliver 100 GPA. Disease severity was assessed in 2009 and 2010 as the percentage of scab lesion coverage on a single fruit at each cardinal direction, below and above the midline of the tree canopy (eight ratings/tree), every 14 or 28 days (depending on trial and location). Ratings for each tree were averaged to a single value. Disease progression was analyzed using area under the disease progress curve (AUDPC) by season for all treatments (23). Once fully mature, nuts were removed from each tree using a tractor-mounted tree shaker (Savage Equipment) and harvested using an orchard floor harvester (Savage Equipment). Yield data were collected after field cleaning and drying pecan nuts to $6.5 \%$ moisture in 2009 and $4.5 \%$ moisture in 2010 .

1994-96 Fruit severity data. Fruit disease severity data were collected during the 1994-96 growing seasons by Dr. G. F. Driever (7). Rating sites included Sparks (1995-96), Burneyville (199495), and Vinita (1994-95), OK. Disease severity data were collected using a modified Horsfall-Barratt scale ranging from 1 (disease free) to 8 (100\% fruit severity) (7). Fruit severity was rated per cluster across arbitrary locations of the tree canopy. Values as determined by the ordinal scale were converted to percentages by using the midpoint indicated by each range of the rating scale. Ratings for each tree were averaged to a single value. These data were used previously to develop the original model. They were reused here to further explore other models and modeling approaches.

Weather variables. Weather data for the 1994-96 and 2009-10 growing seasons were collected from the Oklahoma Mesonet weather stations in closest proximity to each rating site. These sites included Sparks (1995-96), Burneyville (1994-95), Vinita (199495), Perkins (2009-10), and Madill (2009-10), OK. Moving averages based on time between disease assessments were calculated from average daily weather data. Time intervals between disease ratings were 7,14 , or 28 days depending on location and study. The weather variables evaluated included air temperature, relative humidity, dew point, dew point depression, total solar radiation, and daily rainfall total. Dew point depression was calculated as the absolute difference between air temperature and dew point. Rainfall was further converted to a binomial variable where a "no-rain" event was coded as 0 and a "rain" event of $\geq 2.5 \mathrm{~mm}$ was coded as a 1 . Both total daily rainfall and binomial rain variables were used in the model development process.

Model development. For development of scab prediction models, disease severity data were converted to a binomial variable where ratings $\geq 25 \%$ were coded as 1 and all other events as 0 . Previous research demonstrated that an acceptable threshold for determining economically damaging levels of pecan scab on fruit was approximately $25 \%$ severity (12). Because multiple disease assessments were collected on the same tree throughout the season, all models were developed using the generalized estimating equations procedure (PROC GENMOD with the REPEATED statement) in SAS (version 9.2; SAS Institute) to account for the correlated nature of the data $(14,30)$. Unadjusted effects were calculated for use in the model building process and significance was determined using a $\chi^{2}$.

For this analysis, QIC was used in determining overall fit and proper working correlation matrix. QICu was used to determine proper parameterization of the models. During the build process, models with the smallest QIC and QICu were selected. Smaller $\mathrm{QIC}$ and $\mathrm{QICu}$ indicate better model fit (18). All models were 
developed using a forward selection process beginning with the most significant unadjusted effect.

\section{Results}

2009 and 2010 Field trials. Following the prepollination fungicide application, fungicides were applied twice during the 2009-10 growing season for the $21.1^{\circ} \mathrm{C} / 90 \%$ treatment. Fungicide applications were made four times (following the prepollination spray) for the remaining treatments for both years (Table 1). Because of low and varying levels of disease in the 2009 growing season, there were no significant differences in final disease severity or AUDPC recorded among treatments (Table 2). However, numerically larger values of final disease severity and AUDPC were recorded in the nontreated and $15.5^{\circ} \mathrm{C} / 85 \%$ treatments compared with the $21.1^{\circ} \mathrm{C} / 90 \%$ treatment. Yield differences ranged from 100 to 170 $\mathrm{kg} / \mathrm{ha}$ and were not significantly different among treatments (Fig. 1A). In 2010, the highest levels of disease were observed in plots not treated with fungicide (Table 2). All plots that were sprayed with fungicides had significantly less disease and lower AUDPC values than the nonsprayed treatments. Yield differences were not significantly different among all treatments. However, yield tended to be higher in plots treated with fungicide (Fig. 1B).

Model development. Analysis of the single-effects models demonstrated that relative humidity was the most significant unadjusted effect followed by dew point depression, whereas temperature and daily accumulated rain were not effects that explained the probability of pecan scab (Table 3). Because of previous research indicating the biological significance of temperature and total accumulated rain on pecan scab development, these variables where forced into one model during the building process. A second model was developed using dew point and dew point depression rather than temperature and relative humidity. Subsequent full- and reducedmodel testing indicated that the full main effects model was statistically the best fit, and biologically and meteorologically relevant for the temperature/relative humidity models developed (Table 4). A reduced model was most appropriate for the dew point/dew point depression models developed to describe the probability of a significant (fruit severity $\geq 25 \%$ ) pecan scab event (Table 5 ). In the dew point/dew point depression model, the full main effects model that included dew point, dew point depression, solar radiation, and the binomial rain variable was the statistically best-fitting model as determined by the lowest QICu (Table 5). However, there was a negative influence of dew point depression in the full main effects model. Therefore, a reduced model that included dew point, dew point depression, and the binomial rain variable was selected as the most appropriate model. In order for dew point to be an appropriate parameter for addition to the model, a reference to the temperature must be included in the model. Although dew point is the point at which atmospheric saturation occurs, the proximity of the ambient temperature to the dew point must be included. The smaller the dew point depression gets, the more likely it is that a dew event will occur.

To further evaluate both models and use the temperature/relative humidity model to test the validity of using $21.1^{\circ} \mathrm{C}$ temperature and $90 \%$ relative humidity thresholds in the current OAPSFA, temperature or relative humidity and dew point or dew point depres- sion were held constant while adjusting the other variable within the back-transformed models. It was assumed that a 0.50 probability of significant pecan scab increase was a suitable action threshold (e.g., probabilities $\geq 0.50$ indicated that disease was likely). For the temperature/relative humidity model, temperature, relative humidity, and the binomial rain variable were positively correlated to an increasing probability of observing significant levels of pecan scab on fruit. Increasing levels of total solar radiation were inversely correlated with the probability of economically damaging levels of pecan scab. The probability of significant scab increase never approached the 0.50 action threshold when relative humidity was adjusted at a constant temperature of $18^{\circ} \mathrm{C}$, the minimum observed temperature (Fig. 2A). At the mean observed temperature of $21.2^{\circ} \mathrm{C}$, the predicted probability of a significant increase in scab was above 0.50 when relative humidity was $\geq 87 \%$ (Fig. 2B). At the maximum observed temperature of $30.6^{\circ} \mathrm{C}$, the probability of a significant pecan scab event was predicted to be above 0.50 when relative humidity was $\geq 82 \%$ (Fig. 2C). When temperature was
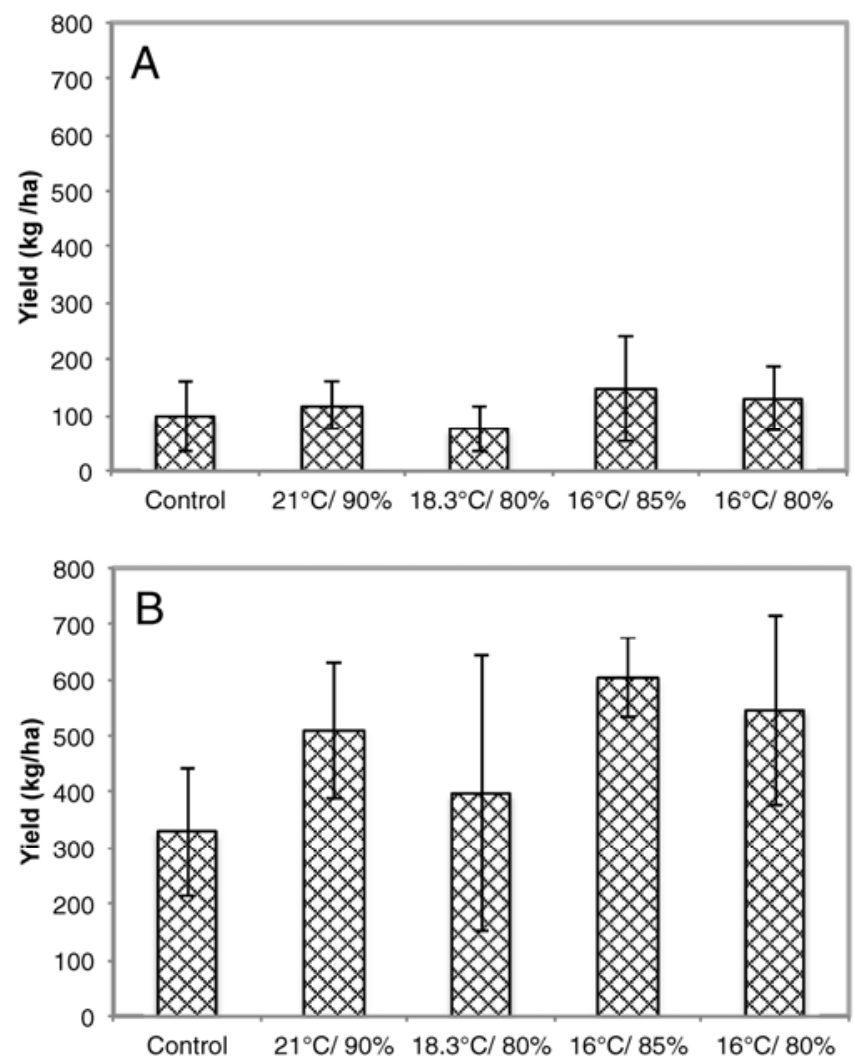

Fig. 1. Pecan yield during the A, 2009 and B, 2010 growing seasons for plots sprayed with fungicide according to the Oklahoma Agweather Pecan Scab Fungicide Advisory using five combinations of air temperature and relative humidity thresholds to calculate "scab hours". Treatments included air temperature/relative humidity thresholds of $15.5^{\circ} \mathrm{C} / 80 \%, 18.3^{\circ} \mathrm{C} / 80 \%, 15.5^{\circ} \mathrm{C} / 85 \%, 21.1^{\circ} \mathrm{C} / 90 \%$, and a nontreated control. Error bars represent a $95 \%$ confidence interval about the treatment mean.

Table 2. Effects of weather-based advisory programs on levels of pecan scab during 2009 and 2010 growing seasons in Madill, OK $^{z}$

\begin{tabular}{|c|c|c|c|c|c|c|}
\hline \multirow[b]{2}{*}{ Treatment } & \multicolumn{3}{|c|}{2009} & \multicolumn{3}{|c|}{2010} \\
\hline & Severity (\%) & AUDPC (\%-days) & Applications & Severity (\%) & AUDPC (\%-days) & Applications \\
\hline Nontreated & 31 & 963.0 & N/A & $57.2 \mathrm{a}$ & $1,589.2 \mathrm{a}$ & N/A \\
\hline $21.1^{\circ} \mathrm{C} / 90 \%$ & 13 & 387.0 & 3 & $26.1 \mathrm{~b}$ & $671.2 \mathrm{~b}$ & 3 \\
\hline $15.5^{\circ} \mathrm{C} / 85 \%$ & 39 & 925.3 & 4 & $12.7 \mathrm{~b}$ & $658.9 \mathrm{~b}$ & 4 \\
\hline $18.3^{\circ} \mathrm{C} / 80 \%$ & 0 & 0.0 & 4 & $13.2 \mathrm{~b}$ & $333.9 \mathrm{~b}$ & 4 \\
\hline $15.5^{\circ} \mathrm{C} / 80 \%$ & 1 & 38.5 & 4 & $11.1 \mathrm{~b}$ & $266.6 \mathrm{~b}$ & 4 \\
\hline
\end{tabular}

${ }^{\mathrm{z}}$ Severity $=$ mean observed fruit severity taken on the final disease rating on 18 September 2009 and 16 August 2010; AUDPC = area under the disease progress curve; Applications = number of fungicide applications; and N/A = not applicable. Mean values within a column followed by the same letter, are not significantly different according to Fisher's protected least significant difference $(\alpha=0.05)$. 
adjusted at a constant relative humidity of 57 or $72 \%$, significant levels of pecan scab were not predicted (Fig. 2D and E). Only when relative humidity was fixed at $87 \%$ were significant increases in pecan scab predicted when temperature was $\geq 23^{\circ} \mathrm{C}$ (Fig. $2 \mathrm{~F}$ ).

In the reduced model that included dew point, dew point depression, and the binomial rain variable, dew point was positively correlated with an increasing probability of observing significant increases in pecan scab. Rain events greater than $2.5 \mathrm{~mm}$ and dew point depression were inversely correlated to an increasing probability of observing significant pecan scab. When dew point was fixed at a constant value of $14.4^{\circ} \mathrm{C}$, the probability of a significant scab event was above the 0.50 action threshold at dew point depression values less than $4^{\circ} \mathrm{C}$ (Fig. 3A). At a fixed dew point of $20.6^{\circ} \mathrm{C}$, the predicted probability of a significant increase in scab was above 0.50 when dew point depression was less than $9^{\circ} \mathrm{C}$ (Fig. 3B). At the maximum observed dew point of $24.4^{\circ} \mathrm{C}$, the probability of a significant pecan scab event was predicted to be above 0.50 at a dew point depression less than $12^{\circ} \mathrm{C}$ (Fig. $3 \mathrm{C}$ ). When dew point was adjusted at a constant dew point depression of $4^{\circ} \mathrm{C}$, significant levels of pecan scab were predicted when dew point was greater than $14^{\circ} \mathrm{C}$ (Fig. 3D). When dew point depression was fixed at $10^{\circ} \mathrm{C}$, significant levels of pecan scab were predicted at dew points greater than $22^{\circ} \mathrm{C}$ (Fig. 3E). When dew point depression was fixed at $18^{\circ} \mathrm{C}$, significant levels of pecan scab were not predicted across any of the observed dew points (Fig. 3F).

\section{Discussion}

This study demonstrates that current thresholds used by the OAPSFA appear to closely estimate scab epidemics in Oklahoma orchards. Field experiments indicated that the $21.1^{\circ} \mathrm{C} / 90 \% \mathrm{RH}$ thresholds were typically suitable for controlling scab to levels that did not influence yield, while providing a two-spray savings over the other spray regimes evaluated in this study. However, there is evidence that there is a slight underestimation of pecan scab when using the current advisory temperature/relative humidity thresholds, which could result in inaccuracies in epidemic prediction. An adjustment of the relative humidity threshold to $87 \%$ may reduce type-II error if assuming an action threshold of 0.50 . Findings by Sentelhas et al. (21) demonstrated that relative humidity could be used to estimate leaf-wetting events when the relative humidity threshold was calibrated to each site. This may be necessary in Oklahoma; however, using a single relative humidity threshold for the entire state would be more straightforward. Relative humidity thresholds $<90 \%$ have also been shown to accurately predict disease in a field situation and maintain a high degree of sensitivity and specificity (16).

The negative influence of solar radiation in the temperature/relative humidity and dew point/dew point depression models presented here is biologically significant. Solar radiation has been shown to inhibit the ability of conidia to germinate in Venturia inaequalis, Cladosporium spp., Alternaria spp., Arthrinium spp., and Aspergillus spp. $(3,26)$.
The effect of rain has been shown to have a dual effect on the capture of spores from the atmosphere (10). Spore liberation has been shown to greatly increase immediately prior to a rain event. During the rain event, spore captures decreased. However, after the rain event, the number of spores captured increased again $(4,5,10,13,27)$. The positive influence of rain in the temperature and relative humidity model reinforces the idea that rain events are highly conducive to the development of epidemics. These events are known to be an indicator of leaf wetness onset and increase relative humidity, resulting in conditions conducive for spore

Table 4. Evaluation of models predicting the probability of a scab event greater than $25 \%$ fruit severity using air temperature $(\mathrm{T})$, relative humidity $(\mathrm{RH})$, total solar radiation (SR), binomial output of rain events (R, where 1 $=$ rain $\geq 2.5 \mathrm{~mm}$ and $0=<2.5 \mathrm{~mm}$ ), and total rainfall $(\mathrm{TR})$ as independent variables $^{\mathrm{x}}$

\begin{tabular}{ll}
\hline Model $^{\mathbf{y}}$ & $\mathbf{Q I C u}^{\mathbf{z}}$ \\
\hline$-12.72+0.1566 \mathrm{RH}$ & 408.81 \\
$-30.12+0.2099 \mathrm{RH}+0.1687 \mathrm{~T}$ & 389.66 \\
$-13.57+0.1799 \mathrm{RH}-1.639 \mathrm{R}$ & 370.40 \\
$-18.63-0.2450 \mathrm{RH}-4.342 \mathrm{TR}$ & 478.50 \\
$-15.30+0.1713 \mathrm{RH}+0.0661 \mathrm{SR}$ & 408.66 \\
$-29.40+0.2286 \mathrm{RH}-1.630 \mathrm{R}+0.1538 \mathrm{~T}$ & 353.95 \\
$-9.540+0.1585 \mathrm{RH}-1.932 \mathrm{R}-0.1021 \mathrm{SR}$ & 369.11 \\
$-33.40+0.1803 \mathrm{RH}+0.3806 \mathrm{~T}-0.5770 \mathrm{SR}+3.39 \mathrm{R}$ & 313.31 \\
\hline
\end{tabular}

${ }^{\mathrm{x}}$ Models were developed using a forward selection approach starting with the most significant unadjusted effect as chosen by the lowest QICu.

y Data used were collected during the 1994-96, 2009, and 2010 growing seasons.

${ }^{\mathrm{z}}$ Quasi-likelihood under the independence curve information criterion adjusted for the number of parameters in the model. Lower values indicate better model fit.

Table 5. Best fitting multivariable models describing the probability of a scab event using dew point depression (DPD), dew point (DP), binomial output of rain events ( $R$, where $1=$ rain event $\geq 2.5 \mathrm{~mm}$ and $0<2.5 \mathrm{~mm}$ ), rain accumulation (TR), and total solar radiation (SR) as independent variables $^{\mathrm{x}}$

\begin{tabular}{ll}
\hline Model $^{\mathbf{y}}$ & $\mathbf{Q I C u}^{\mathbf{z}}$ \\
\hline $2.11-0.3219 \mathrm{DPD}$ & 416.36 \\
$-17.91+0.2405 \mathrm{DP}$ & 433.02 \\
$-9.6818-0.2735 \mathrm{DPD}+0.1624 \mathrm{DP}$ & 397.85 \\
$-7.567-0.3252 \mathrm{DPD}+0.1517 \mathrm{DP}-1.542 \mathrm{R}$ & 364.59 \\
$-11.36-0.2061 \mathrm{DPD}+0.2122 \mathrm{DP}-0.1093 \mathrm{SR}$ & 396.27 \\
$-5.715-0.4233 \mathrm{DPD}+0.1341 \mathrm{DP}-3.220 \mathrm{R}$ & 381.27 \\
$-12.53+0.3771 \mathrm{DP}-3.340 \mathrm{R}-0.5809 \mathrm{SR}$ & 317.77 \\
$-12.91+0.0231 \mathrm{DPD}+0.3859 \mathrm{DP}-3.394 \mathrm{R}-0.6005 \mathrm{SR}$ & 319.70 \\
\hline
\end{tabular}

${ }^{\mathrm{x}}$ Models were developed using a forward selection approach starting with the most significant unadjusted effect as chosen by the lowest $\mathrm{QICu}$.

${ }^{y}$ Data used were collected during the 1994-96, 2009, and 2010 growing seasons.

${ }^{\mathrm{z}}$ Quasi-likelihood under the independence curve information criterion adjusted for number of parameters in the model. Lower values indicate better model fit.

Table 3. Single-effects models describing the probability of a scab event greater than $25 \%$ fruit severity using either dew point (DP), air temperature (T), relative humidity $(\mathrm{RH})$, total solar radiation (SR), binomial output of rain events ( $\mathrm{R}$, where $1=$ rain event $\geq 2.5 \mathrm{~mm}$ and $0=<2.5 \mathrm{~mm}$ ), and total rainfall (TR) as independent variables

\begin{tabular}{|c|c|c|c|c|}
\hline Model $^{x}$ & $\mathrm{QIC}^{\mathbf{y}}$ & $\mathrm{QICu}^{\mathrm{z}}$ & $\chi^{2}$ & $P$ value \\
\hline$-12.72+0.1566 \mathrm{RH}$ & 411.39 & 408.81 & 29.30 & $<0.0001$ \\
\hline $2.11-0.3219 \mathrm{DPD}$ & 419.39 & 416.36 & 28.30 & $<0.0001$ \\
\hline$-17.91+0.2405 \mathrm{DP}$ & 438.98 & 433.02 & 13.40 & 0.0003 \\
\hline$-0.31-1.47 \mathrm{R}$ & 442.6 & 437.65 & 11.98 & 0.0005 \\
\hline $0.91-0.093 \mathrm{SR}$ & 476.89 & 471.53 & 8.84 & 0.0029 \\
\hline$-1.13-0.2809 \mathrm{TR}$ & 481.50 & 476.60 & 0.46 & 0.4958 \\
\hline$-.7197-0.0058 \mathrm{~T}$ & 482.76 & 477.25 & 0.07 & 0.7906 \\
\hline
\end{tabular}

${ }^{x}$ Data used were collected during the 1994-96, 2009, and 2010 growing seasons.

${ }^{y}$ Quasi-likelihood under the independence model information criterion. Lower values indicate better model fit.

${ }^{z}$ Quasi-likelihood under the independence model information criterion adjusted for the number of parameters in the model. Lower values indicate better model fit. 
liberation and infection events (11). The approach used by the AUPecan advisory is based on the occurrence of rain and has been used successfully since its adaptation. Light misting rain allows deposition of spores on leaf surfaces but does not generate sufficient force to coalesce droplets and wash spores from them (20). However, the dew point model shows decreased probability of economically damaging disease levels during rain events. This relationship can be explained by washing events that take place during significant rainstorms. In previous research, rain events measuring 23 and $33 \mathrm{~mm}$ resulted in a decrease in concentrations of airborne Cladosporium spp. spores (24). These findings were amplified if rain events occurred during the late night hours. Dur- ing prolonged heavy rain events, spores can also be washed from the leaf surface to the grassy understory of the orchard $(1,2,17)$.

The dew point/dew point depression model developed during the course of this study has provided insight into predicting pecan scab epidemics while relying on a more appropriate meteorological phenomenon to estimate leaf-wetting events that occur in the absence of rain. Few studies have looked at the importance of dew point depression when estimating leaf wetness for use in a fungicide advisory, although the importance of dew on epidemics has been well documented (29). Continued work on the validation of this technique in needed in order to better understand the ability of dew point depression to predict epidemics. Dew point depressions
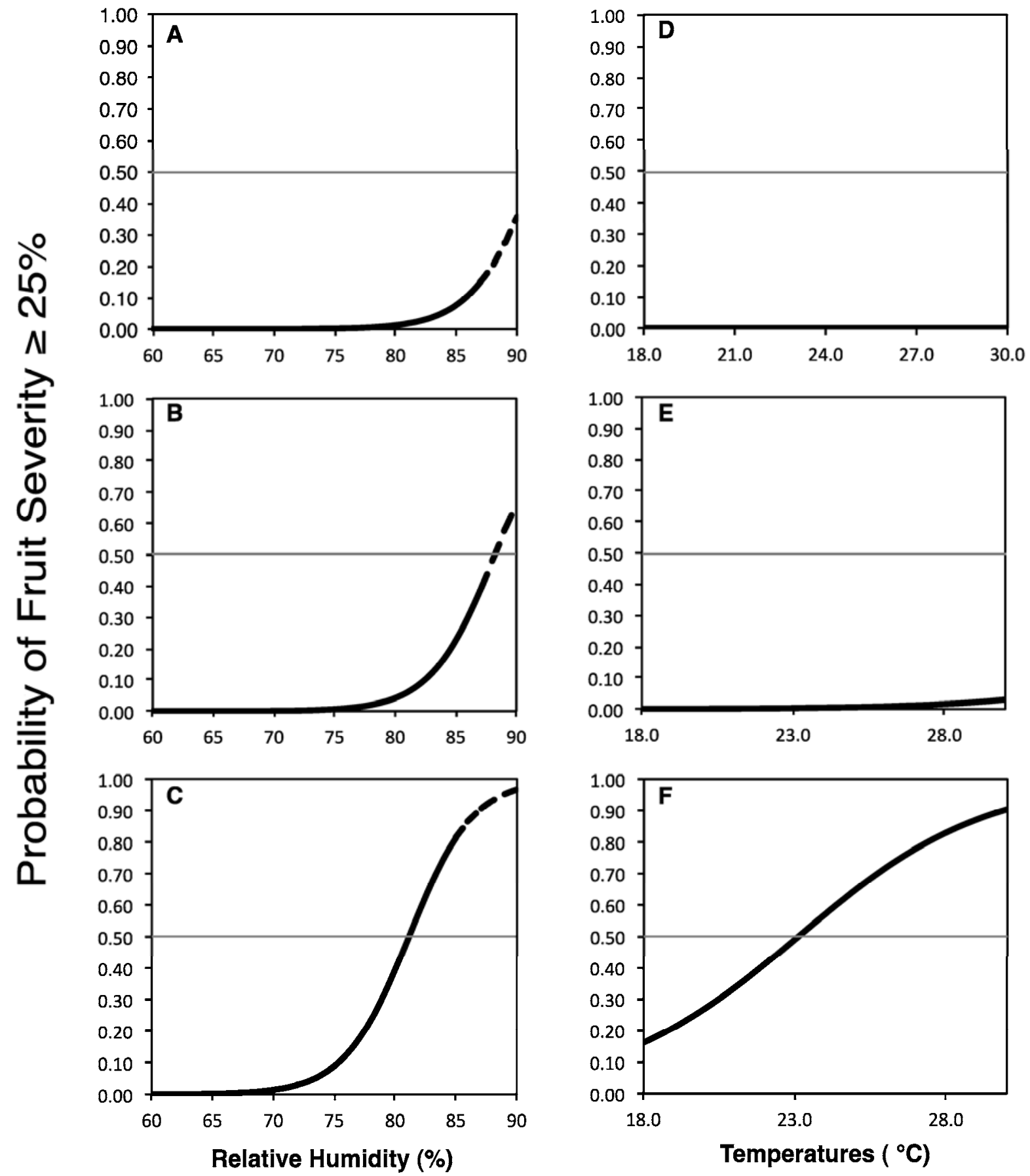

Fig. 2. Evaluation of best fitting temperature/relative humidity-based model that included temperature (T), relative humidity (RH), total solar radiation (SR), and a binomial rain variable $(R)$ where $1=\geq 2.5 \mathrm{~mm}$ of rain and $0=<2.5 \mathrm{~mm}$ of rain. Probability of a significant fruit severity event (fruit severity $\geq 25 \%$ ) as predicted by the model: fruit severity $\geq 25 \%=-\exp (-33.40+0.1803 \mathrm{RH}+0.3806 \mathrm{~T}-0.5770 \mathrm{SR}+3.39 \mathrm{R}) /[1+\exp (-33.40+0.1803 \mathrm{RH}+0.3806 \mathrm{~T}-0.5770 \mathrm{SR}+3.39 \mathrm{R})]$ when T was fixed at the observed A, minimum $\left(18.0^{\circ} \mathrm{C}\right)$; $\mathbf{B}$, mean $\left(21.2^{\circ} \mathrm{C}\right)$; and $\mathbf{C}$, maximum $\left(30.6^{\circ} \mathrm{C}\right)$ values and $\mathrm{RH}$ was adjusted or when $\mathrm{RH}$ was fixed at the observed $\mathbf{D}$, minimum $(57 \%)$; $\mathbf{E}$, mean $(72 \%)$; and $\mathbf{F}$, maximum $(87 \%)$ values and T was adjusted. All predictions assumed no rain (e.g., $R=0$ ) and total $S R$ held constant at the mean observed level of $22.5 \mathrm{MJ} / \mathrm{m}^{2}$. Dotted lines represent probabilities extrapolated outside the context of the observed data. The horizontal line is positioned at the action threshold of 0.50 . 
less than $1.8^{\circ} \mathrm{C}$ have been proposed as an estimator of leaf wetness onset and dew point depression greater than $2.2^{\circ} \mathrm{C}$ as leaf wetness dry-off (19). These values were compared with a relative humidity threshold of $90 \%$ and an extended relative humidity threshold model using $87 \%$ as the base in another study (22). Those findings demonstrated that, when thresholds were calibrated specifically to each site, the dew point depression and relative humidity threshold approaches were suitable and capable of predicting leaf wetness duration with an accuracy of less than $2 \mathrm{~h}$ difference between predicted and observed leaf wetness duration, which made this approach suitable for operational use.
The temperature/relative humidity model presented here not only offers insight into the performance of the OAPSFA but also may have an advantage over the current threshold approach if it was used directly to predict pecan scab increases. This model has been adjusted for the effects of solar radiation and the accumulation of rain in a dynamic fashion. By doing so, it is evident that the thresholds used by the current advisory closely estimated periods of scab increase; however, accuracy might be improved by adding the effects of solar radiation and rain. Furthermore, a new model using dew point and dew point depression was developed. Future validation studies using these models should be performed to iden-
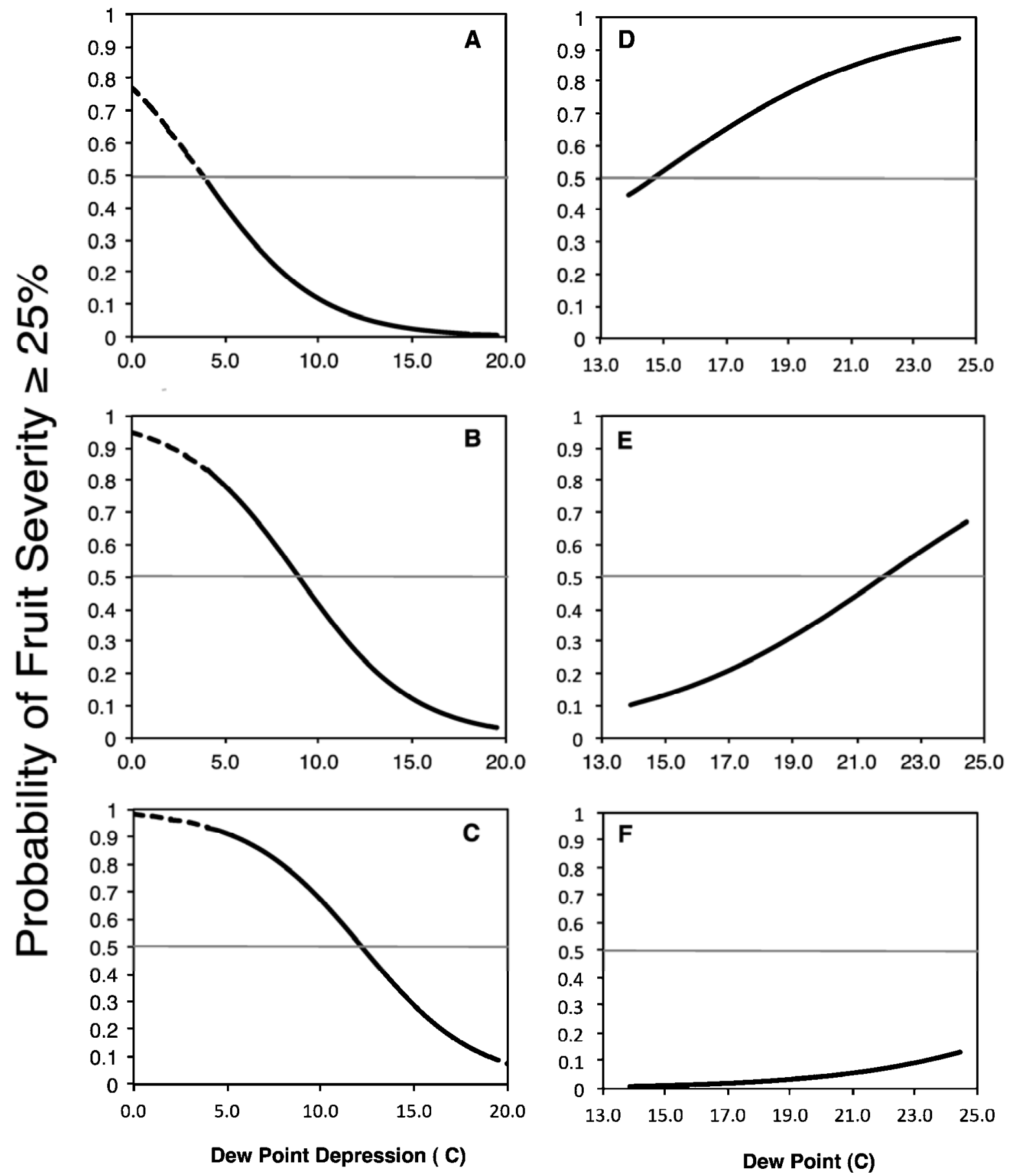

Fig. 3. Evaluation of most appropriate dew point/dew point depression-based model that included dew point (DP), dew point depression (DPD), and a binomial rain variable (R) where $1=\geq 2.5 \mathrm{~mm}$ of rain and $0=<2.5 \mathrm{~mm}$ of rain. Probability of a significant fruit severity event as predicted by the model: fruit severity $\geq 25 \%=-\exp (-5.715-0.4233$ $\mathrm{DPD}+0.1341 \mathrm{DP}-3.220 \mathrm{R}) /[1+\exp (-5.715-0.4233 \mathrm{DPD}+0.1341 \mathrm{DP}-3.220 \mathrm{R})]$ when DP was fixed at the observed $\mathbf{A}$, minimum $\left(14.4^{\circ} \mathrm{C}\right) ; \mathbf{B}$, mean $\left(20.6^{\circ} \mathrm{C}\right) ;$ and $\mathbf{C}$, maximum $\left(24.4^{\circ} \mathrm{C}\right)$ values and DPD was adjusted or when DPD was fixed at the observed $\mathrm{D}$, minimum $\left(4^{\circ} \mathrm{C}\right) ; \mathrm{E}$, mean $\left(10^{\circ} \mathrm{C}\right)$; and $\mathrm{F}$, maximum $\left(18^{\circ} \mathrm{C}\right)$ values and $\mathrm{DP}$ was adjusted. All predictions assumed no rain (e.g., $\mathrm{R}=0$ ). Dashed lines represent probabilities extrapolated outside the context of the observed data. The horizontal line is positioned at the action threshold of 0.50 . 
tify any improvement in the ability to predict fungicide applications.

\section{Acknowledgments}

Published with the approval of the Director, Oklahoma Agricultural Experiment Station, Stillwater. This project was supported, in part, by the Oklahoma Agricultural Experiment Station Project 2667. We thank the Oklahoma Pecan Growers Association for partially funding this project, G. Driever for access to historical data, and the Hauani Creek Ranch for field support.

\section{Literature Cited}

1. Aylor, D. E. 1998. The aerobiology of apple scab. Plant Dis. 82:838-849.

2. Aylor, D. E., and Jie, Q. 1996. Micrometeorological determination of release rate of Venturia inaequalis ascospores from a ground-level source during rain. Agric. For. Meteorol. 81:157-178.

3. Aylor, D. E., and Sanogo, S. 1997. Germinability of Venturia inaequalis conidia exposed to sunlight. Phytopathology 87:628-633.

4. Aylor, D. E., and Sutton, T. B. 1992. Release of Venturia inaequalis ascospores during unsteady rain: relationship to spore transport and deposition. Phytopathology 82:532-540.

5. Burch, M., and Levetin, E. 2002. Effects of meteorological conditions on spore plumes. Int. J. Biometeorol. 46:107-117.

6. Demaree, J. B. 1924. Pecan scab with special reference to sources of the early spring infection. J. Agric. Res. 28:321-330.

7. Driever, G. F. 1998. Development of a threshold model for scheduling fungicide applications to control pecan scab. Ph.D. dissertation, Oklahoma State University. http://search.proquest.com/docview/304482382/fulltext PDF?accountid=4117.

8. Gottwald, T. R. 1985. Influence of temperature, leaf wetness period, leaf age, and spore concentration on infection of pecan leaves by conidia of Cladosporium caryigenum. Phytopathology 75:190-194.

9. Gottwald, T. R., and Bertrand, P. F. 1983. Effect of time of inoculation with Cladosporium caryigenum on pecan scab development and nut quality. Phytopathology 73:714-718.

10. Hjelmroos, M. 1993. Relationship between airborne fungal spore presence and weather variables-Cladosporium and Alternaria. Grana 32:40-47.

11. Huber, L., and Gillespie, T.J. 1992. Modeling leaf wetness in relation to plant disease epidemiology. Annu. Rev. Phytopathol. 30:553-577.

12. Hunter, R. E. 1983. Influence of scab on late season nut drop of pecans. Plant Dis. 67:806-807.

13. Kurkela, T. 1997. The number of Cladosporium conidia in the air in different weather conditions. Grana 36:54-61.
14. Liang, K. Y., and Zeger, S. L.1986. Longitudinal data analysis using generalized linear models. Biometrika 73:13-22.

15. Monteith, J. L. 1957. Dew. J. R. Meteorol. Soc. 83:322-341.

16. Mwakutuya, E., and Banniza, S. 2010. Influence of temperature and wetness periods on the development of stemphylium blight on lentil. Plant Dis. 94:1219-1224.

17. Nicholson, K. W. 1988. A review of particle resuspension. Atmos. Environ. 22:2639-2651.

18. Pan, W. 2001. Akaike's information criterion in generalized estimating equations. Biometrics 57:120-125.

19. Rao, P. S., Gillespie, T. J., and Schaafsma, A. W. 1998. Estimating wetness on maize ears from meteorological observations. Can. J. Soil Sci. 78:149-154.

20. Rich, S., and Waggoner, P. E. 1962. Atmospheric concentration of Cladosporium spores. Science 137:962-965.

21. Sentelhas, P. C., Dalla Marta, A., Orlandini, S., Santos, E. A., Gillespie, T. J., and Gleason, M. L. 2008. Suitability of relative humidity as an estimator of leaf wetness duration. Agric. For. Meteorol. 148:392-400.

22. Sentelhas, P. C., Gillespie, T. J., Gleason, M. L., Monteiro, J. E. B. A., and Helland, S. T. 2004. Operational exposure of leaf wetness sensors. Agric. For. Meteorol. 126:59-72.

23. Shaner, G., and Finney, R. E. 1977. The effect of nitrogen fertilization on the expression of slow-mildewing resistance in Knox wheat. Phytopathology 67:1051-1056.

24. Troutt, C., and Levetin, E. 2001. Correlation of spring spore concentrations and meteorological conditions in Tulsa, Oklahoma. Int. J. Biometeorol 45:64-74.

25. Turechek, W. W., and Stevenson, K. L. 1998. Effects of host resistance, temperature, leaf wetness, and leaf age an infection and lesion development of pecan scab. Phytopathology 88:1294-1301.

26. Ulevicius, V., Peciulyte, D., Lugauskas, A., and Andriejauskiene, J. 2004 Field study on changes in viability of airborne fungal propagules exposed to UV radiation. Environmental Toxicology 19:437-441.

27. Venables, K. M., Allitt, U., Collier, C.G., Emberlin, J., Greig, J.B., Hardaker, P. J., Highham, J. H., Latng-Morton, T., Maynard, R. L., Murray, V. Strachan, D., and Tee, R. D. 1997. Thunderstorm-related asthma-the epidemic of 24/25 June 1994. Clin. Exp. Allergy 27:725-736.

28. von Brembson, S. Smith, D. L., Carlson, J. D., Sutherland, A., and Hoey, M. Mesonet Agweather Pecan Scab Advisor Description. Oklahoma State University.

29. Wallin, J. R. 1967. Agrometeorological aspects of dew. Agric. Meteorol. 4:85-102.

30. Zeger, S. L., and Liang, K. Y. 1986. Longitudinal data analysis for discrete and continuous outcomes. Biometrics 42:121-130. 